\title{
Estimation of energy expenditure of Nordic walking: a crossover trial
}

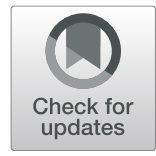

Sora Baek ${ }^{1,2^{*}}$ (1) and Yuncheol Ha ${ }^{1}$ (D)

\begin{abstract}
Background: Nordic walking (NW) requires more energy compared with conventional walking (W). However, the metabolic equation for NW has not been reported. Therefore, this study aimed to characterize responses in oxygen uptake, minute ventilation, heart rate, systolic blood pressure, and surface electromyography of the upper and lower limb muscles during NW and W and develop a metabolic equation for energy expenditure $\left(E, \mathrm{~mL} \cdot \mathrm{kg}^{-1} \cdot \mathrm{min}^{-1}\right)$ of NW.

Methods: This study was performed in a randomized, controlled, crossover design to test the energy expenditure during NW and W. Fifteen healthy young men were enrolled (aged $23.7 \pm 3.0$ years). All participants performed two randomly ordered walking tests (NW and W) on a treadmill at a predetermined stepwise incremental walking speed $\left(3-5 \mathrm{~km} \cdot \mathrm{h}^{-1}\right.$ ) and grade (0-7\%). The oxygen uptake, minute ventilation, heart rate, systolic blood pressure, and surface electromyography signals of the three upper limb muscles and three lower limb muscles in their right body were recorded and compared between NW and W using paired-t test. Multiple linear regression analysis was used to draw estimation of $E$ during $W$ and $N W$.
\end{abstract}

Results: Oxygen uptake $(+15.8 \%)$, minute ventilation $(+17.0 \%)$, heart rate $(+8.4 \%)$, and systolic blood pressure $(+7.7 \%)$ were higher in NW than in W $(P<.05)$. NW resulted in increased muscle activity in all of the upper limb muscles $(P<.05)$. In the lower limb, surface electromyography activities in two of the three lower limb muscles were increased in NW than in W only during level walking $(P<.05)$. Energy expenditure during $W$ and NW was estimated as follows: $E_{N W}=6.1+0.09 \times$ speed $+1.19 \times$ speed $\times$ grade and $E_{W}=4.4+0.09 \times$ speed $+1.20 \times$ speed $\times$ grade .

Conclusion: NW showed higher work intensity than $\mathrm{W}$, with an oxygen consumption difference of $1.7 \mathrm{~mL} \cdot \mathrm{kg}^{-1} \cdot \mathrm{min}^{-1}$. The coefficients were not different between the two walking methods. NW involved more muscles of the upper body than W.

Keywords: Electromyography, Energy metabolism, Heart rate, Nordic walking, Oxygen consumption

\section{Background}

Nordic walking $(\mathrm{NW})$ is a type of walking with alternating movements of the arms and hands pushing off NW poles [1]. NW exerts beneficial effects on resting heart rate, blood pressure, exercise capacity, maximal oxygen consumption, and quality of life in patients with various

\footnotetext{
* Correspondence: sora.baek@kangwon.ac.kr

'Department of Rehabilitation Medicine, Kangwon National University Hospital, Baengnyeong-ro 156, Chuncheon-si, Gangwon-do 24289, Republic of Korea

${ }^{2}$ Department of Rehabilitation Medicine, Kangwon National University School of Medicine, Kangwondaehak-gil 1, Chuncheon-si, Gangwon-do 24341, Republic of Korea
}

diseases including diabetes mellitus, obesity, chronic obstructive pulmonary disease, and Parkinson's disease [2]. A systematic review and meta-analysis reported that NW showed promising results in cardiovascular disorders compared to non-active control and suggested incorporation of NW for cardiovascular rehabilitation [3].

NW showed remarkable walking characteristics compared to conventional walking (W). It was known that the stride length increases and the number of steps decreases during NW than in W in the same speed. There were greater vertical oscillations of potential and kinetic energy for NW than for W [4]. For energy consumption, participants in NW consumed more energy than $\mathrm{W}$ in

C The Author(s). 2021 Open Access This article is licensed under a Creative Commons Attribution 4.0 International License, which permits use, sharing, adaptation, distribution and reproduction in any medium or format, as long as you give appropriate credit to the original author(s) and the source, provide a link to the Creative Commons licence, and indicate if changes were made. The images or other third party material in this article are included in the article's Creative Commons licence, unless indicated otherwise in a credit line to the material. If material is not included in the article's Creative Commons licence and your intended use is not permitted by statutory regulation or exceeds the permitted use, you will need to obtain permission directly from the copyright holder. To view a copy of this licence, visit http://creativecommons.org/licenses/by/4.0/ The Creative Commons Public Domain Dedication waiver (http://creativecommons.org/publicdomain/zero/1.0/) applies to the data made available in this article, unless otherwise stated in a credit line to the data. 
the same speed. The NW was able to improve the metabolic economy of walking reducing the cost-of-transport and increasing the optimal walking speed and selfselected walking speed [5, 6]. The use of poles actively engaged the upper body to propel the person forward during walking, resulting in higher activation of the upper body musculature $[6,7]$, and NW increases cardiovascular metabolism compared with $\mathrm{W}$ at the same walking speed [8]. These acute differences result in better movement pattern from upper limbs, increasing arm oscillations and reducing the muscle co-contraction from upper limbs [6]. When the differences in oxygen consumption between NW and W were reported as \% difference, the degree of increased oxygen consumption, however, varied from 7 to $23 \%$ during flat walking [912]. In contrast, not proportional to the increase in energy expenditure during NW, the subjectively perceived exertion was not significantly increased $[8,11]$.

To our knowledge, metabolic equation of NW has not been reported. NW walking showed higher oxygen consumption compared to W, regardless of the walking speed. During uphill walking, NW also showed a greater amount of oxygen consumption than W; however, the extents of the increase in energy expenditure were reduced when walking uphill than flat walking $[7,8]$.

When incorporating NW in exercise training of patients, the intensity of exercise should be considered, and exact energy expenditure-estimation of NW would be required for both flat and uphill walking. Energy expenditure during exercise is estimated as the sum of the resting, horizontal, and vertical components. Regarding walking exercise, the metabolic calculation equation with walking speed $\left(\mathrm{m} \cdot \mathrm{min}^{-1}\right)$ and fractional grade was proposed as $E\left(\mathrm{~mL} \cdot \mathrm{kg}^{-1} \cdot \mathrm{min}^{-1}\right)=3.5+0.1 \times$ speed $+1.8 \times$ speed $\times$ fractional grade (the American College of Sports Medicine (ACSM) equation) [13]

NW requires more energy than W; however, its metabolic equation has not been reported. We hypothesized that the energy consumption of Nordic walking could be derived from the horizontal and vertical values of walking. This study aimed to measure the metabolic, cardiovascular, and muscular responses during $\mathrm{NW}$ and $\mathrm{W}$ on a treadmill at incremental speed and grade. Moreover, we aimed to derive a metabolic equation for NW's energy expenditure $(E)$, which includes the horizontal and vertical elements (gait speed and slope, respectively).

\section{Methods}

\section{Study design and participants}

This study was performed in a randomized, controlled, crossover design to the metabolic, cardiovascular, and muscular responses during NW and W (Fig. 1a). The experiment was conducted in a laboratory setting within 1 day, with no follow-up. Healthy adults over the age of 19 who had no Nordic pole experience were recruited as study subjects. Those with a history of arrhythmia, heart failure, or myocardial infarction or those who received treatment or medication for cardiovascular disease within the last 3 months were excluded from the study. We assumed the oxygen consumption of $18.3 \mathrm{~mL} \cdot \mathrm{kg}^{-1} \cdot \mathrm{min}^{-1}$ for $\mathrm{W}$ and $20.5 \mathrm{~mL} \cdot \mathrm{kg}^{-1} \cdot \mathrm{min}^{-1}$ for NW (standard deviation during $\mathrm{W}, 2.5 \mathrm{~mL} \cdot \mathrm{kg}^{-1} \cdot \mathrm{min}^{-1}$ ) [11]. The estimated sample size was 11 , with an alpha level of 0.05 and a beta level of 0.20 . We expected a $30 \%$ dropout rate, and the final sample size was calculated as 16 . The first participant was recruited on March 24, 2018. The experiment was completed by May 31, 2018, with a total of 16 people. During the experiment, 1 subject was not tested for surface electromyography; hence, the final analysis included the results of 15 subjects.

The experimental group constituted 15 healthy men. Table 1 shows the means and standard deviations for age, weight, body mass index, waist circumference, umbilicus height, resting systolic and diastolic blood pressure (SBP and $\mathrm{DBP}$, respectively), resting heart rate (HR), room temperature, and room humidity. All participants had no experience with NW before this study and were fully informed about the study's procedures and their participation's possible risks. All voluntarily participated in the study after they provided written consent. This study was approved by the Institutional Review Board. It was conducted together with a study that analyzed the accuracy of HR measurement using a wearable band during NW [14].

\section{NW technique}

Participants visited the exercise testing laboratory on the day of the graded walking tests. Participants were sent a homepage link (http://www.nordicwalking.or.kr) about the Nordic walking method in advance to the experimental day. On experiment day, they underwent a 1-h training on holding and releasing the Nordic pole and walked with Nordic pole on surface and on the treadmill with a NW instructor from the Korean Nordic Walking Federation/Korean Walking Association (Y. Ha) before the walking test. The NW technique emerged from a training modality that is typical of cross-country skiing, requiring a specific technique: moving the extended arms similar to the range of movement of natural walking, maintaining the upper body upright, maintaining a backward pole position during the loading phase, using the poles actively and dynamically, and controlling the poles by hands gripping with grasp/release patterns [15]. Each participant's pole length (Nordic Friend, Gabel, Italy) was set at the umbilicus height. The weight of the walking pole was $196 \mathrm{~g}$. After familiarization with NW on a treadmill, they were asked to rest for at least 30 min before the start of the walking test. 


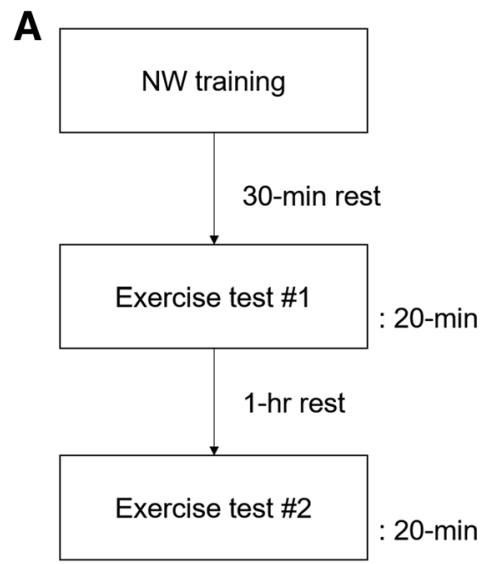

\begin{tabular}{|c|c|c|c|c|}
\hline \multicolumn{2}{|c|}{ Stage } & Duration (min) & $\begin{array}{l}\text { Treadmill } \\
\text { speed }(\mathrm{km} / \mathrm{h})\end{array}$ & $\begin{array}{l}\text { Treadmill } \\
\text { grade (\%) }\end{array}$ \\
\hline \multicolumn{2}{|c|}{ Rest } & 2 & 0 & 0 \\
\hline \multicolumn{2}{|c|}{ Adaptation } & 2 & 2 & 0 \\
\hline \multirow[t]{7}{*}{ Walking } & Stage 1 & 2 & 3 & 0 \\
\hline & Stage 2 & 2 & 4 & 0 \\
\hline & Stage 3 & 2 & 5 & 0 \\
\hline & Stage 4 & 2 & 5 & 1 \\
\hline & Stage 5 & 2 & 5 & 3 \\
\hline & Stage 6 & 2 & 5 & 5 \\
\hline & Stage 7 & 2 & 5 & 7 \\
\hline \multicolumn{2}{|c|}{ Recovery } & 2 & 0 & 0 \\
\hline \multicolumn{2}{|c|}{ Total } & 20 & & \\
\hline
\end{tabular}

Fig. 1 Study protocol. a. Flow of two random-ordered walking tests. b. Walking test protocol

\section{Graded walking test protocol}

The graded walking test protocol on the treadmill constituted 20-min stages of rest, adaptation, walking, and recovery. The participants warmed up and familiarized for $2 \mathrm{~min}$ at $2 \mathrm{~km} \cdot \mathrm{h}^{-1}$, the same speed with the first walking test stage. The walking tests constituted seven stages, with a 2-min duration for each stage: walking on a treadmill (STEX 8100TD; Taeha Mechatronics, Anyang-Si, Korea) at $3 \mathrm{~km} \cdot \mathrm{h}^{-1}, 4 \mathrm{~km} \cdot \mathrm{h}^{-1}$, and $5 \mathrm{~km} \cdot \mathrm{h}^{-1}$ at $0 \%$ inclination and $1,3,5$, and $7 \%$ inclination at 5 $\mathrm{km} \cdot \mathrm{h}^{-1}$ (Fig. 1b).

The participants walked on the treadmill at a stepwise incremental speed and grade. Two walking conditions (NW and W) were used with a randomized sequence using a random number. The blood pressure cuff was worn on the left upper arm, and SBP/DBP were measured at the end of each stage. HR was assessed in 30-s intervals using 12-lead electrocardiography (Philips StressVue, Philips, the Netherlands), and the highest HR

Table 1 Characteristics of participants and laboratory room conditions $(N=15)$

\begin{tabular}{lll}
\hline & Mean \pm SD & (Min-Max) \\
\hline Age (years) & $23.7 \pm 3.0$ & $(19-30)$ \\
Height $(\mathrm{cm})$ & $174.6 \pm 4.9$ & $(167.2-182.6)$ \\
Weight $(\mathrm{kg})$ & $76.3 \pm 13.9$ & $(57-111.9)$ \\
Body mass index $\left(\mathrm{kg} / \mathrm{m}^{2}\right)$ & $25.0 \pm 4.1$ & $(18.9-34.5)$ \\
Waist circumference $(\mathrm{cm})$ & $86.9 \pm 10.7$ & $(72-104.5)$ \\
Umbilicus height $(\mathrm{cm})$ & $104.9 \pm 3.6$ & $(98-113)$ \\
Resting SBP $(\mathrm{mmHg})$ & $124.4 \pm 10.6$ & $(110-146)$ \\
Resting DBP $(\mathrm{mmHg})$ & $78.9 \pm 7.0$ & $(65-88)$ \\
Resting HR (beat $/ \mathrm{min})$ & $83.2 \pm 8.3$ & $(73-99)$ \\
Room temperature $\left({ }^{\circ} \mathrm{C}\right)$ & $25.9 \pm 1.6$ & $(23.4-28.2)$ \\
Room humidity $(\%)$ & $33.0 \pm 11.2$ & $(21-61)$ \\
\hline
\end{tabular}

SBP systolic blood pressure, $D B P$ diastolic blood pressure, $H R$ heart rate value was selected for each walking stage. Exertion was also rated at each walking stage; they were rated using the 6-20-point Borg rating of perceived exertion (RPE) scale [16].

\section{Ventilatory gas analysis}

The oxygen consumption $\left(\dot{V} \mathrm{O}_{2}\right)$, carbon dioxide production $\left(\dot{V} \mathrm{CO}_{2}\right)$, expired ventilation per minute $(\dot{V} \mathrm{E})$, respiratory exchange ratio (RER), and respiratory rate (RR) were measured using a ventilatory gas analysis system (Ultima PFX ${ }^{\circ}$ MGC Diagnostics Corporation, St Paul, MN, USA). The measured values during the 2 min of each walking stage were averaged.

\section{Surface electromyography}

The surface electromyographic signals of the mid deltoid (DEL, the midpoint between the acromion and the deltoid tubercle), biceps brachii ( $\mathrm{BB}$, the thickest muscle belly of $\mathrm{BB}$ ), triceps brachii ( $\mathrm{TB}$, the midpoint between the acromion and the olecranon), vastus lateralis (VL, five finger's breadth upward and lateral from the patella), medial gastrocnemius (GCM, the medial belly of the calf muscle), and tibialis anterior (TA, four finger's breadth downward from the tibial tuberosity) in their right body were recorded using Model 586 Desktop DTS Receiver and Model 542 Desktop DTS EMG Sensor (Noraxon USA, Inc., Scottsdale, AZ).

Before applying the surface electrodes, the skin was cleaned with an alcohol swab to reduce impedance. A skilled physiotherapist attached all electrodes to the skin on the midpoint of the contracted muscle belly parallel to the muscle fibers with an adhesive tape. The sampling frequency was $1500 \mathrm{~Hz}$. The data were band-pass filtered with a $10-250 \mathrm{~Hz}$ and rectified in the acquisition software (myoRESEARCH $\left.{ }^{\circ} 3\right)$. The root mean square value was acquired for each walking stage. 


\section{Statistical analysis}

The acquired data were analyzed using the SPSS ver. 23 (IBM, Armonk, NY). Hemodynamic responses, ventilatory gas analysis, and surface electromyographic results were compared between NW and $\mathrm{W}$ using the paired $\mathrm{t}$ test. A $P$-value $<0.05$ was considered significant.

Simple and multiple linear regression analyses were conducted to estimate $E$ for NW. The $\dot{V} \mathrm{O}_{2}\left(\mathrm{~mL} \cdot \mathrm{kg}^{-1}\right.$. $\mathrm{min}^{-1}$ ) with different walking speeds at flat walking (walking stage 1 to 3 ; grade $=0 \%$; speed 3 to $5 \mathrm{~km} \cdot \mathrm{h}^{-1}$ or 50 to $83 \mathrm{~m} \cdot \mathrm{min}^{-1}$ ) was analyzed using a simple linear regression analysis. The $\dot{V O}_{2}$ in different grades with constant speed (walking stage 3 to 7 ; speed $=5 \mathrm{~km} \cdot \mathrm{h}^{-1}$ or $83 \mathrm{~m} \cdot \mathrm{min}^{-1}$ ) was estimated using a simple linear regression analysis. Multiple linear regression analysis was used for walking stage 1 to 7 for treadmill speed and the interaction of treadmill speed and grade.

$E$ for $\mathrm{W}$ also estimated with simple and multiple linear regression analyses in the same way as NW.

\section{Results}

\section{Ventilatory gas analysis, HR, and blood pressure during} graded NW and W

Ventilatory gas analysis results showed increased metabolism and hemodynamic responses in NW than in W. The $\dot{V} O_{2}(+15.8 \%), \dot{V} C O_{2}(+17.0 \%), \dot{V} E(+17.0 \%), \mathrm{RR}$ $(+18.2 \%), \mathrm{SBP}(+7.7 \%), \mathrm{DBP}(+6.9 \%)$, and $\mathrm{HR}(+8.4 \%)$ were significantly higher in NW than in $\mathrm{W}(P$-value $<$ 0.05) (Table 2). $\dot{V} \mathrm{O}_{2}, \dot{V} \mathrm{E}, \mathrm{HR}$, and SBP showed significant differences between NW and $\mathrm{W}$ in all walking stages (Fig. 2). Conversely, RPE was less in NW than in W (Table 2). Chest pain was absent in both NW and W.
The degree of difficulty in breathing was very low, with no significant difference between NW and W.

\section{Activation of the upper and lower limb muscles during graded NW and $\mathrm{W}$}

The differences in muscle activities between $\mathrm{W}$ and NW varied between the upper and lower extremities. The upper limb muscle activities (DEL, BB, and TB) were significantly higher in NW than in W $(P$-value $<0.05)$ (Table 2). These differences were significant in all walking stages (Fig. 3). No significant difference was found in the activity of VL between the two walking conditions (Table 2) in lower extremity muscles. TA and GCM activities were higher in NW (Table 3); however, it showed a significant difference only in level walking (stages 1 and 2 for TA; stage 1 for GCM) (Fig. 3).

\section{Estimation of oxygen consumption of NW and W}

Ventilatory gas analysis results during NW and $W$ showed that the oxygen uptake was $10.9 \pm 2.2$ to $21.2 \pm$ $1.7 \mathrm{~mL} \cdot \mathrm{kg}^{-1} \cdot \mathrm{min}^{-1}$ during $\mathrm{NW}$ and $9.0 \pm 1.5$ to $19.0 \pm$ $1.4 \mathrm{~mL} \cdot \mathrm{kg}^{-1} \cdot \mathrm{min}^{-1}$ during W. The difference between $\mathrm{NW}$ and $\mathrm{W}$ regarding oxygen consumption from stage 1 to 7 ranged $1.7-2.3 \mathrm{~mL} \cdot \mathrm{kg}^{-1} \cdot \mathrm{min}^{-1}$ (Table 3).

The $E$ or $\dot{V} O_{2}\left(\mathrm{~mL} \cdot \mathrm{kg}^{-1} \cdot \mathrm{min}^{-1}\right)$ during NW with different walking speeds at flat walking (walking stage 1 to 3 ; grade $=0 \%$; speed 3 to $5 \mathrm{~km} \cdot \mathrm{h}^{-1}$ or 50 to $83 \mathrm{~m} \cdot \mathrm{min}^{-1}$ ) was analyzed using a simple linear regression analysis, and coefficients for walking speed were estimated (Table 4, Fig. 4a). Speed is expressed in $\mathrm{m} \cdot \mathrm{min}^{-1}$, and fractional grade is grade percentage expressed in decimal formal (e.g., $10 \%=0.10$ ):

Table 2 Ventilatory gas analysis and surface electromyographic results during Nordic walking (NW) and conventional walking (W)

\begin{tabular}{|c|c|c|c|c|c|}
\hline & NW & w & $P$-value & $\Delta(\mathrm{NW}-\mathrm{W})$ & $\Delta(\mathrm{NW}-\mathrm{W}) / \mathrm{W}(\%)$ \\
\hline$\overline{\mathrm{V}} \mathrm{O}_{2}\left(\mathrm{~mL} \cdot \mathrm{kg}^{-1} \cdot \mathrm{min}^{-1}\right)$ & $15.5 \pm 3.9$ & $13.5 \pm 3.7$ & $<.01$ & $2.0 \pm 1.6$ & 15.8 \\
\hline$\dot{\mathrm{V}} \mathrm{CO}_{2}\left(\mathrm{~mL} \cdot \mathrm{min}^{-1}\right)$ & $968.9 \pm 300.0$ & $840.3 \pm 281.2$ & $<.01$ & $128.6 \pm 111.4$ & 17.0 \\
\hline$\dot{V} E\left(L \cdot m^{-1}\right)$ & $25.0 \pm 6.9$ & $21.6 \pm 6.1$ & $<.01$ & $3.4 \pm 3.3$ & 17.0 \\
\hline RER & $0.823 \pm 0.058$ & $0.815 \pm 0.069$ & $<.05$ & $0.007 \pm 0.035$ & 1.1 \\
\hline RR (beat $\cdot \mathrm{min}^{-1}$ ) & $24.6 \pm 3.5$ & $21.0 \pm 3.1$ & $<.01$ & $3.5 \pm 3.8$ & 18.2 \\
\hline $\mathrm{SBP}(\mathrm{mmHg})$ & $144.5 \pm 11.5$ & $134.5 \pm 11.2$ & $<.01$ & $10 \pm 9.1$ & 7.7 \\
\hline $\mathrm{DBP}(\mathrm{mmHg})$ & $79.2 \pm 5.5$ & $74.4 \pm 5.1$ & $<.01$ & $4.9 \pm 5.9$ & 6.9 \\
\hline HR (beat.min ${ }^{-1}$ ) & $115.8 \pm 14.4$ & $106.9 \pm 13.2$ & $<.01$ & $8.8 \pm 5.6$ & 8.4 \\
\hline RPE & $8.3 \pm 2.6$ & $9.0 \pm 2.7$ & $<.01$ & $-0.6 \pm 1.4$ & -5.9 \\
\hline DEL $(\mu \mathrm{V})$ & $12.0 \pm 4.8$ & $6.7 \pm 3.7$ & $<.01$ & $5.3 \pm 3.1$ & 94.9 \\
\hline $\mathrm{BB}(\mu \mathrm{V})$ & $18.9 \pm 7.2$ & $5.6 \pm 4.5$ & $<.01$ & $13.3 \pm 8.8$ & 381.4 \\
\hline $\mathrm{TB}(\mu \mathrm{V})$ & $21.8 \pm 10.1$ & $6.4 \pm 3.2$ & $<.01$ & $15.4 \pm 9.2$ & 308.6 \\
\hline$V L(\mu V)$ & $65.4 \pm 57.7$ & $67.6 \pm 57.9$ & .60 & $-2.2 \pm 39.1$ & 34.7 \\
\hline $\mathrm{TA}(\mu \mathrm{V})$ & $45.7 \pm 14.4$ & $40.9 \pm 11.3$ & $<.01$ & $4.8 \pm 9.8$ & 13.3 \\
\hline GCM $(\mu V)$ & $39.7 \pm 11.8$ & $36.5 \pm 12.3$ & $<.01$ & $3.3 \pm 6.8$ & 11.7 \\
\hline
\end{tabular}

$R E R$ respiratory exchange ratio, $R R$ respiratory rate, $S B P$ systolic blood pressure, $D B D$ diastolic blood pressure, $H R$ heart rate, $R P E$ rating of perceived exertion, $D E L$ deltoid, $B B$ biceps brachii, $T B$ triceps brachii, $V L$ vastus lateralis, $T A$ tibialis anterior, GCM gastrocnemius, $L 3$ L3 paraspinals 


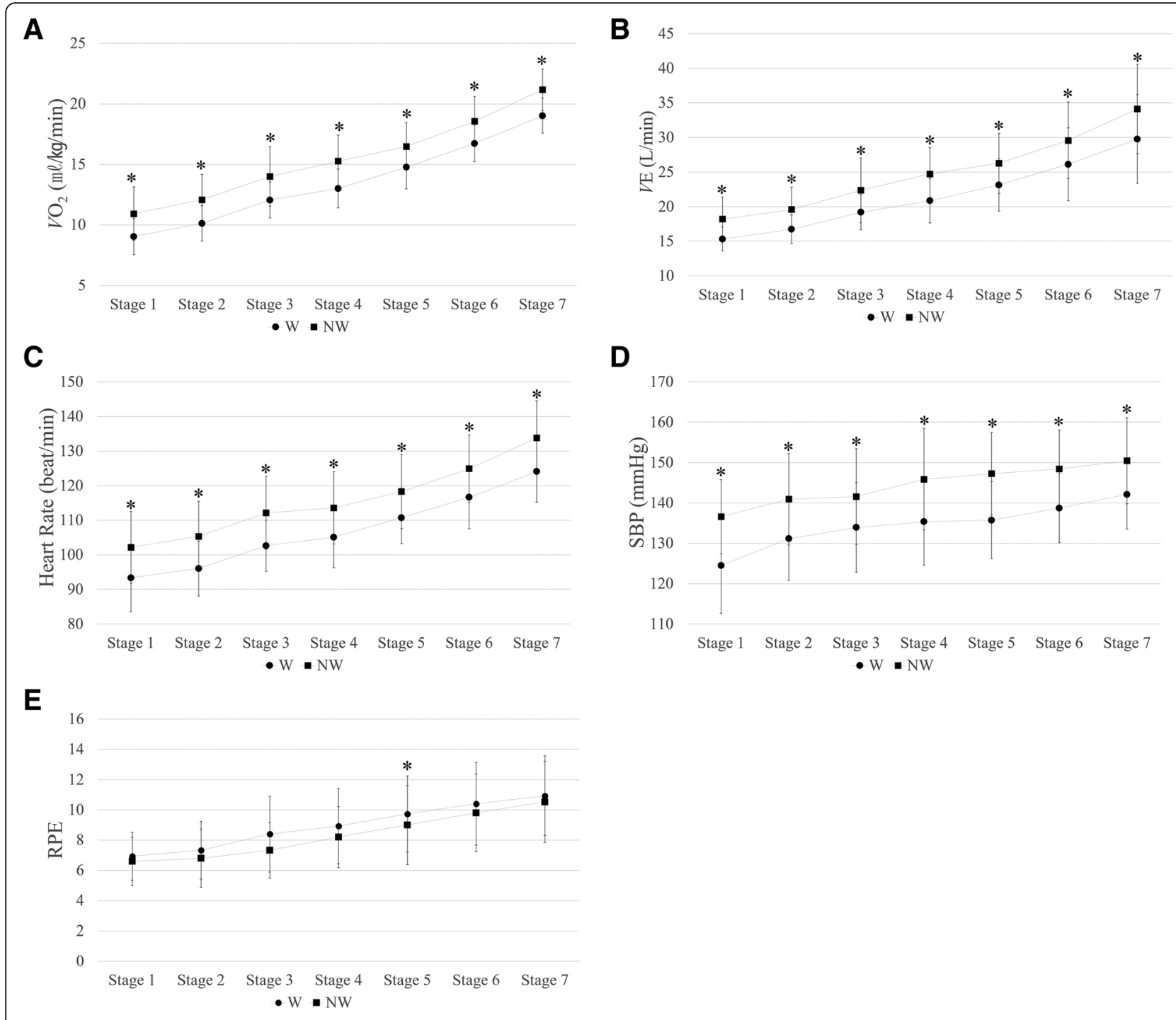

Fig. 2 Ventilatory gas analysis results during walking (W) and Nordic walking (NW). a. Oxygen uptake (VंO2). b. Ventilation (VEE). c. Heart rate. d. Systolic blood pressure (SBP). e. Rate of perceived exertion (RPE). ${ }^{*} P<.05$

$$
E_{N W}=6.3+0.09 \times \text { speed }
$$

Oxygen consumption during NW in different grades with constant speed (walking stage 3 to 7; speed $=5 \mathrm{~km} \cdot \mathrm{h}^{-1}$ or $83 \mathrm{~m} \cdot \mathrm{min}^{-1}$ ) was estimated using a simple linear regression analysis, and coefficients for fractional grade were estimated (Table 4, Fig. $4 b)$ :

$$
E_{N W}=13.9+99.2 \times \text { fractional grade }
$$

Coefficient 0.09 for speed and speed value (83.3 $\mathrm{m} \cdot \mathrm{min}^{-1}$ ) were integrated to the equation:

$$
\begin{aligned}
E_{N W}= & (13.9-7.5)+7.5+(99.2 / 83.3) \times 83.3 \\
& \times \text { fractional grade }=6.4+0.09 \times 83.3 \mathrm{~m} \cdot \mathrm{min}^{-1} \\
& +1.19 \times 83.3 \mathrm{~m} \cdot \mathrm{min}^{-1} \times \text { fractional grade }
\end{aligned}
$$

Simple linear regression analyses were conducted to estimate $E$ for $\mathrm{W}$ in the same way as NW.

$$
\begin{aligned}
E_{W}=4.4 & +0.09 \times \text { speed }(\text { walking stage } 1 \text { to } 3) E_{W}=11.9 \\
E_{W}= & (11.9-7.5)+7.5+(100.1 / 83.3) \\
& +100.1 \times \text { fractional grade }(\text { walking stage } 3 \text { to } 7) \\
& \times 83.3 \times \text { fractional grade }=4.4+0.09 \times 83.3 \mathrm{~m} \cdot \mathrm{min}^{-1} \\
& +1.20 \times 83.3 \mathrm{~m} \cdot \mathrm{min}^{-1} \times \text { fractional grade }
\end{aligned}
$$

From the estimation equations from the two-step simple linear regression analysis, the constant values was 6.4 for NW and 4.4 for $\mathrm{W}$, and the difference was 2.0 $\mathrm{mL} \cdot \mathrm{kg}^{-1} \cdot \mathrm{min}^{-1}$. Coefficients for speed were 0.09 in both 


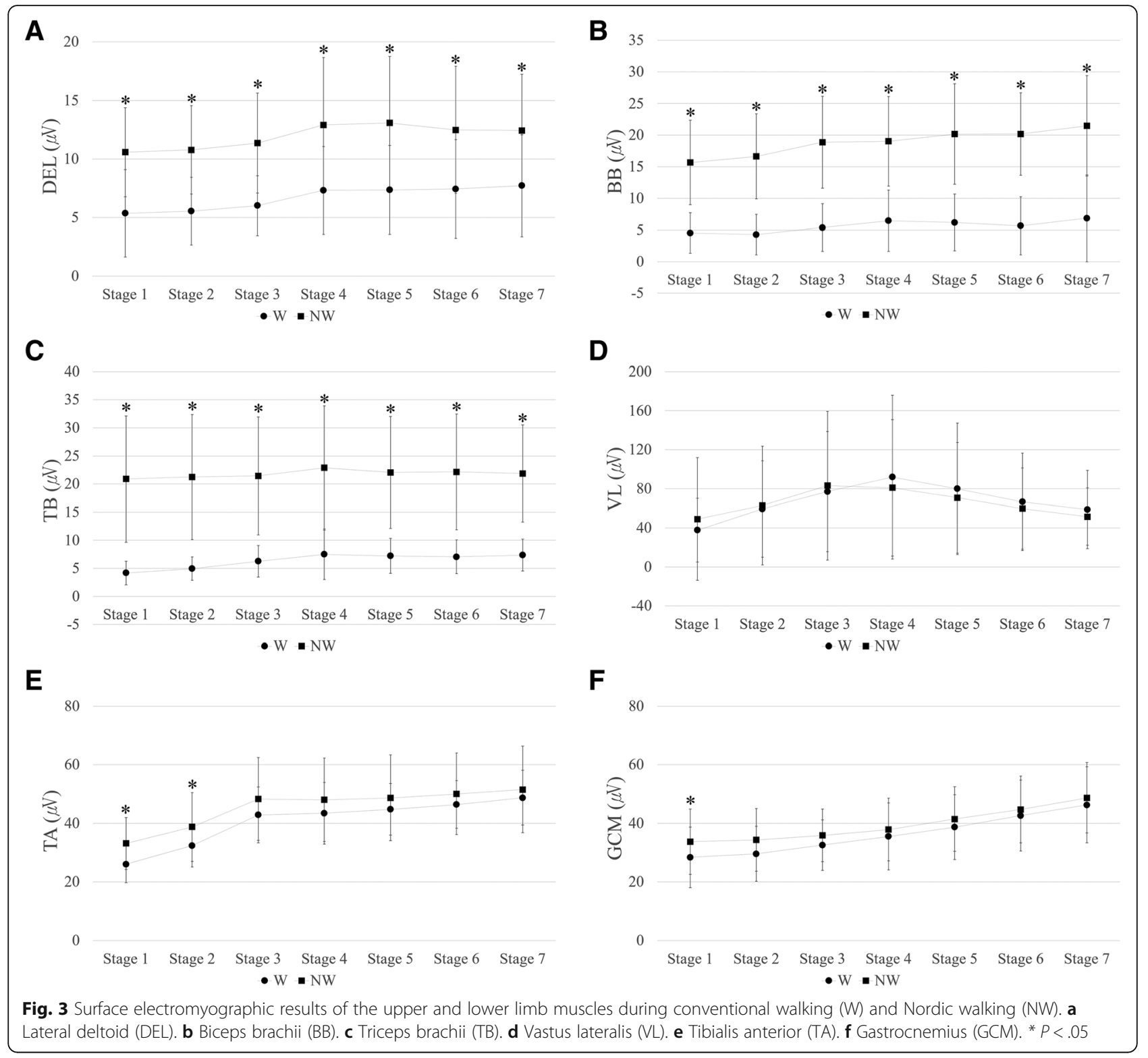

Table 3 Oxygen consumption $\left(\mathrm{VO}_{2}, \mathrm{~mL} \cdot \mathrm{kg}^{-1} \cdot \mathrm{min}^{-1}\right)$ at each walking stage during Nordic walking (NW) and conventional walking (W)

\begin{tabular}{|c|c|c|c|c|c|c|}
\hline Walking stage & Treadmill speed $\left(\mathrm{km} \cdot \mathrm{h}^{-1}\right)$ & Treadmill grade (\%) & $\dot{\mathrm{V}} \mathrm{O}_{2} \mathrm{NW}$ & $\dot{\mathrm{V}} \mathrm{O}_{2} \mathrm{~W}$ & $\Delta \dot{V} \mathrm{O}_{2}\left(\% \dot{V O O}_{2}\right)$ & $P$-value \\
\hline Stage 1 & 3 & 0 & $10.9 \pm 2.2$ & $9.0 \pm 1.5$ & $1.9(20.9)$ & $<.01$ \\
\hline Stage 2 & 4 & 0 & $12.1 \pm 2.1$ & $10.1 \pm 1.5$ & 2.0 (19.3) & $<.01$ \\
\hline Stage 3 & 5 & 0 & $14.0 \pm 2.5$ & $12.0 \pm 1.5$ & $2.0(16.2)$ & $<.01$ \\
\hline Stage 4 & 5 & 1 & $15.3 \pm 2.1$ & $13.0 \pm 1.6$ & $2.3(17.4)$ & $<.01$ \\
\hline Stage 5 & 5 & 3 & $16.5 \pm 2.0$ & $14.8 \pm 1.8$ & 1.7 (11.6) & $<.01$ \\
\hline Stage 6 & 5 & 5 & $18.6 \pm 2.0$ & $16.7 \pm 1.5$ & 1.8 (10.9) & $<.01$ \\
\hline Stage 7 & 5 & 7 & $21.2 \pm 1.7$ & $19.0 \pm 1.4$ & $2.1(11.3)$ & $<.01$ \\
\hline
\end{tabular}



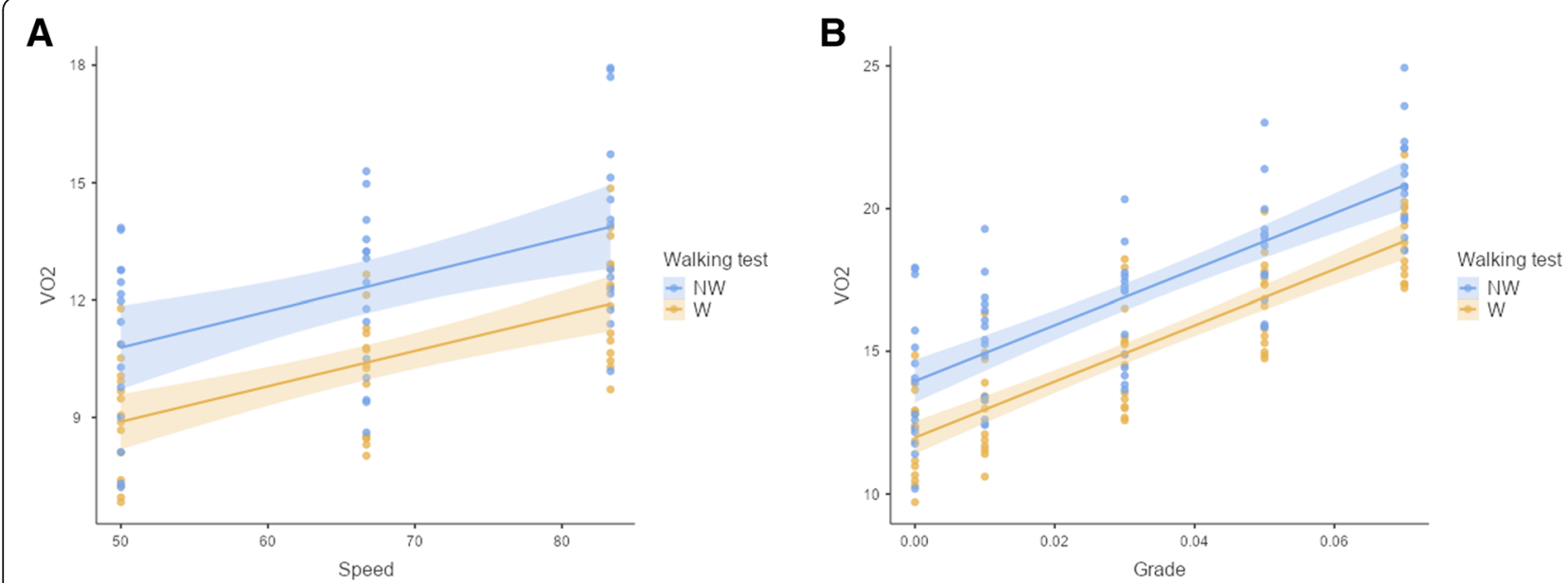

Fig. 4 Scatter plots of $\mathrm{VO}_{2}$ (regression line with standard error) in different walking speeds (a) and grades (b) in Nordic walking (NW) and conventional walking $(\mathrm{W})$

NW and W. Coefficients for fractional grade were 1.19 for NW and 1.20 for W.

As a result of multiple linear regressions for speed and speed $\times$ fractional grade, the final formulae for NW and $\mathrm{W}$ is shown below (Table 5):

$$
\begin{aligned}
E_{N W}\left(\mathrm{~mL} \cdot \mathrm{kg}^{-1} \cdot \mathrm{min}^{-1}\right)= & 6.1+0.09 \\
& \times \text { speed }\left(\mathrm{m} \cdot \mathrm{min}^{-1}\right) \\
& +1.19 \times \text { speed } \\
& \times \text { fractional grade } \\
E_{W}\left(\mathrm{~mL} \cdot \mathrm{kg}^{-1} \cdot \min ^{-1}\right)= & 4.4+0.09 \\
& \times \text { speed }\left(\mathrm{m} \cdot \min ^{-1}\right) \\
& +1.20 \times \text { speed } \\
& \times \text { fractional grade }
\end{aligned}
$$

Both final formulae were statistically significant, explaining $72.0 \%$ of the relationship between $\dot{V} \mathrm{O}_{2}-\mathrm{NW}$ and speed, speed $\times$ fractional grade, and $82.6 \%$ of the relationship between $\dot{V} \mathrm{O}_{2}-\mathrm{W}$ and speed, speed $\times$ fractional grade. The constant value in the final equation for $\mathrm{W}$ was 4.4; this was somewhat higher than the known resting oxygen consumption $\left(3.5 \mathrm{~mL} \cdot \mathrm{kg}^{-1} \cdot \mathrm{min}^{-1}\right)[13]^{\cdot}$ The coefficient for speed was 0.09 , which was similar to the known value of 0.1 [13] However, the coefficient for grade $\times$ speed was 1.2 , which was less than the known value of 1.8 [13] In the above estimation, NW required more oxygen consumption than $\mathrm{W}$, and the difference of constants of the two formulae was $1.7 \mathrm{~mL} \cdot \mathrm{kg}^{-1} \cdot \mathrm{min}^{-1}$ in multiple linear regression analysis. The coefficients for speed and speed $\times$ fractional grade were not different

\begin{tabular}{|c|c|c|c|c|c|c|c|c|c|}
\hline & \multicolumn{5}{|c|}{ Walking stage (treadmill grade $=0.00$ ) } & \multicolumn{4}{|c|}{ Linear regression analysis } \\
\hline & Stage 1 & Stage 2 & & Stage 3 & & Constant & Coefficients for speed & $\mathrm{R}$ & $R^{2}$ \\
\hline Treadmill speed & $50.0 \mathrm{~m} \cdot \mathrm{min}^{-1}\left(3 \mathrm{~km} \cdot \mathrm{h}^{-1}\right)$ & $66.7 \mathrm{~m} \cdot \mathrm{min}^{-}$ & $1\left(4 \mathrm{~km} \cdot \mathrm{h}^{-1}\right)$ & $83.3 \mathrm{~m} \cdot \mathrm{min}^{-}$ & $\left(5 \mathrm{~km} \cdot \mathrm{h}^{-1}\right)$ & & & & \\
\hline$\dot{\mathrm{V}} \mathrm{O}_{2} \mathrm{NW}$ & $10.9 \pm 0.57$ & $12.1 \pm 0.54$ & & $14.0 \pm 0.64$ & & 6.16 & 0.09 & 0.497 & 0.247 \\
\hline \multirow[t]{3}{*}{$\dot{\mathrm{V}} \mathrm{O}_{2} \mathrm{~W}$} & $9.0 \pm 0.38$ & $10.1 \pm 0.38$ & & $12.0 \pm 0.38$ & & 4.36 & 0.09 & 0.648 & 0.420 \\
\hline & \multicolumn{5}{|c|}{ Walking stage (treadmill speed $=83.3 \mathrm{~m} \cdot \mathrm{min}^{-1}$ ) } & \multicolumn{4}{|c|}{ Linear regression analysis } \\
\hline & Stage 3 & Stage 4 & Stage 5 & Stage 6 & Stage 7 & Constant & Coefficients for grade & $\mathrm{R}$ & $R^{2}$ \\
\hline Treadmill grade & 0.00 & 0.01 & 0.03 & 0.05 & 0.07 & & & & \\
\hline VOO2 NW & $14.0 \pm 0.64$ & $15.3 \pm 0.54$ & $16.5 \pm 0.51$ & $18.6 \pm 0.52$ & $21.2 \pm 0.44$ & 13.9 & 99.2 & 0.757 & 0.573 \\
\hline VंO2 W & $12.0 \pm 0.38$ & $13.0 \pm 0.43$ & $14.8 \pm 0.47$ & $16.7 \pm 0.39$ & $19.0 \pm 0.37$ & 11.9 & 100.1 & 0.821 & 0.675 \\
\hline
\end{tabular}
between the two walking methods.

\section{Discussion}

To the best of our knowledge, this is the first study that has derived the energy consumption of Nordic walking through the horizontal and vertical values of walking.

Table 4 Estimation of oxygen consumption $\left(\dot{\mathrm{V}}_{2}, \mathrm{~mL} \cdot \mathrm{kg}^{-1} \cdot \mathrm{min}^{-1}\right)$ during Nordic walking (NW) and conventional walking (W) using simple linear regression analysis

Values are mean \pm standard error 
Table 5 Estimation of oxygen consumption $\left(\dot{\mathrm{VO}}_{2}, \mathrm{~mL} \cdot \mathrm{kg}^{-1} \cdot \mathrm{min}^{-1}\right)$ during Nordic walking (NW) and conventional walking (W) using multiple linear regression analysis

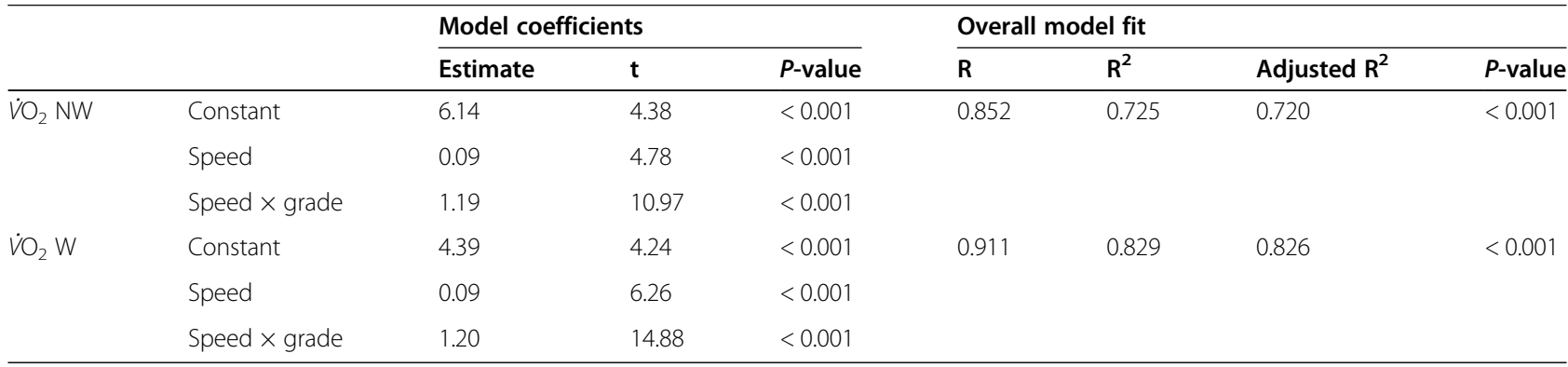

When walking at the given speed and slope, NW had higher exercise intensity than W. The $\dot{V} O_{2}(+15.8 \%)$, $\dot{V} \mathrm{CO}_{2}(+17.0 \%), \quad \dot{V} E(+17.0 \%), \quad \mathrm{RR}(+18.2 \%), \quad \mathrm{SBP}(+$ $7.7 \%)$, DBP $(+6.9 \%)$, and HR (+8.4\%) were significantly higher in NW than in W in all walking stages. In this study, we derived new energy estimation equations of $\mathrm{NW}$ and W from the measured $\dot{V} \mathrm{O}_{2}$ and walking speed and slope: $E_{W}=4.4+0.09 \times$ speed $\left(\mathrm{m} \cdot \mathrm{min}^{-1}\right)+1.20 \times$ speed $\times$ fractional grade and $E_{N W}=6.1+0.09 \times$ speed $\left(\mathrm{m} \cdot \mathrm{min}^{-1}\right)+1.19 \times$ speed $\times$ fractional grade. The constant value in the final equation for $\mathrm{W}$ was $4.4 \mathrm{~mL} \cdot \mathrm{kg}^{-1}$. $\min ^{-1}$, which is somewhat higher than the ACSM equation's known resting oxygen consumption of 3.5 $\mathrm{mL} \cdot \mathrm{kg}^{-1} \cdot \mathrm{min}^{-1}[13]$. The coefficient for speed was 0.09 , which is similar to the known value of 0.1 [13].

Previous studies reported the energy consumption of $\mathrm{NW}$ as a percent difference $\left(\% \dot{V} \mathrm{O}_{2}\right)$ compared to the consumption of $\mathrm{W}$. The result varied depending on the walking speed and the slope from 7 to $23 \%$ during flat walking [9-12]. For uphill walking, Figard-Fabre et al. [8] measured oxygen consumption at 0 and $5 \%$ grade when walking at $4 \mathrm{~km} \cdot \mathrm{h}^{-1}$, and the $\% \dot{V} \mathrm{O}_{2}$ was $16 \%$ at $0 \%$ grade and reduced to $12 \%$ at $5 \%$ grade. In our study, $\% \dot{V} \mathrm{O}_{2}$ was highest in minimum energy expenditure and lowest in maximum energy consumption. Increasing the walking speed from $3 \mathrm{~km} / \mathrm{hr}$. to $5 \mathrm{~km} / \mathrm{hr}$., the $\% \dot{V} \mathrm{O} 2$ of NW compared to W decreased from 20.9 to $16.2 \%$ of W. As the slope of the uphill increased (from 0 to $7 \%$ ) at a constant speed $\left(5 \mathrm{~km} \cdot \mathrm{h}^{-1}\right), \% \dot{V} \mathrm{O} 2$ decreased from the highest (17.4\%) to the lowest (10.9\%). Conversely, the difference $\left(\Delta \dot{V} \mathrm{O}_{2}\right)$ between NW and W was rather constant than proportional. The difference between constants of the two formulae for NW and W was 1.7 $\mathrm{mL} \cdot \mathrm{kg}^{-1} \cdot \mathrm{min}^{-1}$ in multiple linear regression analysis derived from speed and speed $\times$ grade. The results of a study by Figard-Fabre et al. [8] were consistent with the values in our eq. $\left(4 \mathrm{~km} \cdot \mathrm{h}^{-1}, 0 \%, 10.4 \mathrm{~mL} \cdot \mathrm{kg}^{-1} \cdot \mathrm{min}^{-1}\right.$ for $\mathrm{W} ; 12.1 \mathrm{~mL} \cdot \mathrm{kg}^{-1} \cdot \mathrm{min}^{-1}$ for NW; and $16 \%$ for $\% \dot{V} \mathrm{O}_{2} ; 4$ $\mathrm{km} \cdot \mathrm{h}^{-1}, 5 \%, 14.4 \mathrm{~mL} \cdot \mathrm{kg}^{-1} \cdot \mathrm{min}^{-1}$ for W; $16.1 \mathrm{~mL} \cdot \mathrm{kg}^{-1}$. $\mathrm{min}^{-1}$ for NW; and $12 \%$ for $\% \dot{V} \mathrm{O}_{2}$ ). Pellegrini et al. [7] measured oxygen consumption at $15 \%$ grade when walking at $4 \mathrm{~km} \cdot \mathrm{h}^{-1}$, and $\% \dot{V} \mathrm{O}_{2}$ was $6.9 \%$. This value was consistent with that of our eq. $\left(4 \mathrm{~km} \cdot \mathrm{h}^{-1}, 15 \%, 22.4\right.$ $\mathrm{mL} \cdot \mathrm{kg}^{-1} \cdot \mathrm{min}^{-1}$ for $\mathrm{W} ; 24 \mathrm{~mL} \cdot \mathrm{kg}^{-1} \cdot \mathrm{min}^{-1}$ for NW; $7 \%$ for $\% \dot{V} \mathrm{O}_{2}$ ).

The coefficient for walking speed $\times$ grade was 1.20 in our study and smaller than ACSM's coefficient. The ACSM regression equations developed to estimate oxygen uptake have known limitations that lead to overestimation of energy expenditure, particularly at higher work rates [17]' Kokkinos et al. recently developed a new energy equation for walking from the Fitness Registry and the Importance of Exercise National Database (FRIE ND) and suggested small cofficient value of 0.79 for walking speed $\times$ grade: $E\left(\mathrm{~mL} \cdot \mathrm{kg}^{-1} \cdot \mathrm{min}^{-1}\right)=3.5+0.17 \times$ speed $\left(\mathrm{m} \cdot \mathrm{min}^{-1}\right)+0.79 \times$ speed $\times$ fractional grade (FRIE ND equation) [17].

Pellegrini et al. reported that higher total mechanical work for NW mainly due to the greater work required to move the upper limbs and poles [4]. The increase in exercise intensity and oxygen consumption by NW is due to the increased upper limb muscle activity. The upper extremity's increased activity was identified through the surface EMG signals. Walking with upper body exercise [18] can increase the $\dot{V} \mathrm{O}_{2}$. The activities of the upper limb muscles (DEL, BB, and $\mathrm{TB}$ ) were significantly higher in NW than in W. No significant differences were found between the two walking conditions in the lower extremity muscles, except the TA and GCM muscles during slow level walking. Regarding walking while exercising the upper limbs, the amount of oxygen consumption significantly increased compared with normal walking [18]. The increase in oxygen consumption at NW seems to be related to increase in the activity of the upper limb muscles. This result is in line with previous findings $[6,7]$.

Interestingly, oxygen consumption increased significantly in NW compared with W; however, the subjective difficulty, the RPE, did not show a significant difference between NW and W at level walking and rather lower RPE with NW during uphill walking. Previous studies showed higher RPE [9], lower RPE [11], or no difference 
[8] with pole walking compared with W. During uphill walking, decreased RPE with NW was reported in previous studies with pole walking $[8,19]$. According to a study comparing the RPE of NW and W on downhill, uphill, and level walking, the RPE in NW on uphill walking was significantly decreased compared with $\mathrm{W}$ [8].

The formula for oxygen consumption in NW was derived only from a non-fast walking speed $\left(3-5 \mathrm{~km} \cdot \mathrm{h}^{-1}\right)$ and a slope within 7\%. Energy estimation may differ from the predicted values in a faster or higher slope. In addition, NW energy consumption could be influenced by several factors other than walking speed and slope grade. When a relatively short pole was used, energy consumption was increased in the uphill than in the case of a normal length pole [20]. By contrast, pole weight does not appear to have a significant effect on energy consumption [21]. As a result of comparing $\mathrm{W}$ and four different types of NW, muscle activity and metabolic response were different according to the type of NW; however, all types of NW showed higher metabolic response and muscle activity than $\mathrm{W}[22]$.

NW is usually conducted outdoors. We measured indoors on a treadmill. Oxygen consumption results of studies conducted in an environment other than the treadmill (outdoor field study) showed a difference from the predicted value of our formula $[10,12]$ ' Church et al. [10] reported that the average amounts of oxygen consumption were $13.9 \mathrm{~mL} \cdot \mathrm{kg}^{-1} \cdot \mathrm{min}^{-1}$ during $\mathrm{W}$ and 16.7 $\mathrm{mL} \cdot \mathrm{kg}^{-1} \cdot \mathrm{min}^{-1}$ during NW at average self-selected walking speeds $\left(5.6 \mathrm{~km} \cdot \mathrm{h}^{-1}\right.$ for male and $5.9 \mathrm{~km} \cdot \mathrm{h}^{-1}$ for female participants). The values were larger than the estimated $\dot{V} \mathrm{O}_{2}$ values derived from our eq. (12.8 and $13.3 \mathrm{~mL} \cdot \mathrm{kg}^{-1} \cdot \mathrm{min}^{-1}$ for $\mathrm{W}$ and 14.5 and $15.0 \mathrm{~mL} \cdot \mathrm{kg}^{-1}$. $\mathrm{min}^{-1}$ for NW). The oxygen consumption values measured in the field study [10] were greater than our predicted values; particularly, the $\dot{V} \mathrm{O}_{2}$ during NW was higher than the predicted value. Regarding the field test, terrain characteristics would differ from those of a treadmill, potentially causing a difference in poling force or muscle activity. The difference in walking terrain leads to a difference in oxygen consumption during NW [23]. According to a study by Schiffer et al. [23], the oxygen consumption during NW was significantly increased in a naturally grown soccer lawn than concrete.

This study had limitations. We included only young healthy subjects without cardiovascular or neuromuscular disorders; however, the potential target group for therapeutic application of Nordic gait is thought to be the elderly and disables $[3,24]$. The participants of our study were all beginners with no Nordic pole experience and all were young males. The proficiency of NW methods can affect gait technique; however, even after a 4-week NW training three times a week, the difference in oxygen consumption between NW and W did not significantly change before and after the training [8]. Moreover, the activation pattern of the surface electromyography of our results was similar to that of the NWskilled participants. Surface electromyography analysis in participants who were experienced in NW showed that the activities of the $\mathrm{BB}, \mathrm{TB}$, and deltoid anterior in $\mathrm{NW}$ were significantly increased compared with those in W, which was significant in both level and uphill [7]. Furthermore, the activities of the lower extremity muscles, such as the TA, gastrocnemius lateralis, and VL did not show a significant difference in NW and W, which was the same in level and uphill [7]. These muscle activation patterns are similar to those found in our study. According to a previous study, the changes in the aspects of respiratory gas analysis did not differ by sex [9].

We suggest a cautious application of the derived formula to a range other than $3-5 \mathrm{~km} / \mathrm{hr}$. and grade of 0 $7 \%$. In field walking, it should be considered that more energy can be consumed than in a treadmill. We derive the formula only for young men, and we believe that further analysis in women and the elderly is necessary.

\section{Conclusions}

We developed an equation to estimate oxygen consumption during NW, which was constantly consuming more oxygen by $1.7 \mathrm{~mL} \cdot \mathrm{kg}^{-1} \cdot \mathrm{min}^{-1}$. Estimation of oxygen consumption during NW in faster speed is necessary for more precise exercise prescription. The difference in $\dot{V} \mathrm{O}_{2}$ between NW and W was constant both in slow and fast walking speeds and both in level and uphill grades.

\section{Abbreviations}

NW: Nordic walking; W: Conventional walking; $\dot{V}_{2}$ : Oxygen uptake; VE: Minute ventilation; RER: Respiratory exchange ratio; RR: Respiratory rate; DEL: Mid deltoid; BB: Biceps brachii; TB: Triceps brachii; VL: Vastus lateralis; GCM: Medial gastrocnemius; TA: Tibialis anterior; HR: Heart rate; SBP: Systolic blood pressure; DBP: Diastolic blood pressure; sEMG: Surface electromyography; E: Energy expenditure; ACSM: American College of Sports Medicine; RPE: Rating of perceived exertion

\section{Acknowledgements \\ We would like to thank Editage (www.editage.co.kr) for English language editing.}

\section{Authors' contributions}

$\mathrm{SB}$ and $\mathrm{YH}$ designed the research. SB and $\mathrm{YH}$ has performed different parts of the research, analyzed the data, and drafted the paper. SB and $\mathrm{YH}$ contributed to the final analyses, further drafting and critical revision and editing, and final approval of the final version.

\section{Funding}

This work was supported by the National Research Foundation of Korea (NRF) grant from the Korea government (MSIT) (No. NRF-2017R1C1B5076976). The funder had no role in the design of the study, the collection, analysis, and interpretations of data, or in writing the manuscript.

Availability of data and materials

The datasets used and/or analyzed during the current study are available from the corresponding author on reasonable request. 


\section{Ethics approval and consent to participate}

All research activities were reviewed and approved by Kangwon National University Hospital Institutional Review Board (approval number, KNUH-A2017-11-005-003). Written informed consent was obtained from participants prior to study commencement.

\section{Consent for publication}

Not applicable.

\section{Competing interests}

No conflict of interest to declare.

Received: 26 July 2020 Accepted: 3 February 2021

Published online: 19 February 2021

\section{References}

1. Piech K, Piech J, Grants J. Nordic walking - a versatile physical activity fit for everyone (a literature review). LASE J Sport Sci. 2014;5:48-58.

2. Tschentscher M, Niederseer D, Niebauer J. Health benefits of Nordic walking: a systematic review. Am J Prev Med. 2013;44:76-84.

3. Cugusi L, Manca A, Yeo TJ, Bassareo PP, Mercuro G, Kaski JC. Nordic walking for individuals with cardiovascular disease: a systematic review and metaanalysis of randomized controlled trials. Eur J Prev Cardiol. 2017;24:1938-55.

4. Pellegrini B, Peyré-Tartaruga LA, Zoppirolli C, Bortolan L, Savoldelli A, Minetti $A E$, et al. Mechanical energy patterns in nordic walking: comparisons with conventional walking. Gait Posture. 2017;51:234-8.

5. Gomeñuka NA, Oliveira HB, Silva ES, Costa RR, Kanitz AC, Liedtke GV, et al, Effects of Nordic walking training on quality of life, balance and functional mobility in elderly: a randomized clinical trial. PLoS One. 2019;14:1-21.

6. Gomeñuka NA, Oliveira HB, da Silva ES, Passos-Monteiro E, da Rosa RG Carvalho AR, et al. Nordic walking training in elderly, a randomized clinical trial. Part II: biomechanical and metabolic adaptations. Sport Med - Open. 2020;6:1-19

7. Pellegrini B, Peyré-Tartaruga LA, Zoppirolli C, Bortolan L, Bacchi E, FigardFabre $\mathrm{H}$, et al. Exploring muscle activation during Nordic walking: a comparison between conventional and uphill walking. PLoS One. 2015;10: e0138906.

8. Figard-Fabre H, Fabre N, Leonardi A, Schena F. Physiological and perceptual responses to Nordic walking in obese middle-aged women in comparison with the normal walk. Eur J Appl Physiol. 2010;108:1141-51.

9. Porcari JP, Hendrickson TL, Walter PR, Terry L, Walsko G. The physiological responses to walking with and without power poles on treadmill exercise. Res Q Exerc Sport. 1997;68:161-6.

10. Church TS, Earnest CP, Morss GM. Field testing of physiological responses associated with Nordic walking. Res Q Exerc Sport. 2002;73:296-300.

11. Rodgers CD, VanHeest IL, Schachter CL. Energy expenditure during submaximal walking with Exerstriders. Med Sci Sports Exerc. 1995;27:607-11.

12. Schiffer T, Knicker A, Hoffman U, Harwig B, Hollmann W, Strüder HK. Physiological responses to nordic walking, walking and jogging. Eur J Appl Physiol. 2006;98:56-61.

13. Riebe D, editor. ACSM's guideline for exercise testing and prescription. 10th ed. Philadelphia, PA: Wolters Kluwer Health; 2018.

14. Baek $\mathrm{S}, \mathrm{Ha}$ Y, Park H. Accuracy of wearable devices for measuring heart rate during conventional and Nordic walking. PM R. 2020. https://doi.org/10.1 002/pmri.12424. Online ahead of print.

15. Wilhelm A, Mittermaier R, Neureuther C. Nordic walking Praxisbuch. Muenchen: Droemer Knaur; 2006.

16. Borg GA. Psychophysical bases of perceived exertion. Med Sci Sports Exerc. 1982;14:377-81.

17. Kokkinos P, Kaminsky LA, Arena R, Zhang J, Myers J. New generalized equation for predicting maximal oxygen uptake (from the fitness registry and the importance of exercise National Database). Am J Cardiol. 2017;120: 688-92.

18. Butts NK, Knox KM, Foley TS. Energy costs of walking on a dual-action treadmill in men and women. Med Sci Sports Exerc. 1995;27:121-5.

19. Saunders MJ, Hipp GR, Wenos DL, Deaton ML. Trekking poles increase physiological responses to hiking without increased perceived exertion. J Strength Cond Res. 2008;22:1468-74.

20. Hansen EA, Smith G. Energy expenditure and comfort during Nordic walking with different pole lengths. J Strength Cond Res. 2009;23:1187-94.
21. Schiffer T, Knicker A, Montanarella M, Strüder HK. Mechanical and physiological effects of varying pole weights during Nordic walking compared to walking. Eur J Appl Physiol. 2011;111:1121-6.

22. Pellegrini B, Boccia G, Zoppirolli C, Rosa R, Stella F, Bortolan L, et al. Muscular and metabolic responses to different Nordic walking techniques, when style matters. PLoS One. 2018;13:e0195438.

23. Schiffer T, Knicker A, Dannöhl R, Strüder HK. Energy cost and pole forces during Nordic walking under different surface conditions. Med Sci Sports Exerc. 2009:41:663-8.

24. Monteiro EP, Franzoni LT, Cubillos DM, de Oliveira FA, Carvalho AR, Oliveira $H B$, et al. Effects of Nordic walking training on functional parameters in Parkinson's disease: a randomized controlled clinical trial. Scand J Med Sci Sports. 2017;27:351-8.

\section{Publisher's Note}

Springer Nature remains neutral with regard to jurisdictional claims in published maps and institutional affiliations.

\section{Ready to submit your research? Choose BMC and benefit from:}

- fast, convenient online submission

- thorough peer review by experienced researchers in your field

- rapid publication on acceptance

- support for research data, including large and complex data types

- gold Open Access which fosters wider collaboration and increased citations

- maximum visibility for your research: over $100 \mathrm{M}$ website views per year

At $\mathrm{BMC}$, research is always in progress.

Learn more biomedcentral.com/submissions 